\author{
Cadernos de \\ ESTUDOS LNMGǗSTICOS - (54.1), Campinas, Jan./Jun. 2012
}

\title{
SINGULARIDADE NAS MANIFESTAÇÕES DE FALA GAGAS
}

\author{
CÉLIA R. CARNEIRO ${ }^{1}$ \\ ESTER SCARPA ${ }^{2}$
}

\begin{abstract}
RESUMO
A heterogeneidade e imprevisibilidade dos sinais linguísticos presentes em uma fala gaga fazem, de cada manifestação de fala, um acontecimento singular, mas são frequentemente desconsideradas em nome da necessidade de um diagnóstico clínico. Da heterogeneidade, depreende-se a singularidade dos sinais linguísticos que caracterizam essa gagueira e, da imprevisibilidade, descarta-se qualquer possibilidade de controle. Cremos que essas premissas devem estar na base do trabalho de compreensão da gagueira e do início de um diagnóstico em clínica: analisando, interpretando e compreendendo o fenômeno linguístico que faz com que aquela fala seja estranha, incomode ao falante e ao interlocutor. Os dados de dois sujeitos gagos, numa situação de conversa espontânea, foram analisados com relação às manifestações linguísticas de repetições, bloqueios, sons como implosiva dental, clique bilabial, que afetam o contínuo/descontínuo e potencialmente abalam as estuturas métricas da língua. Concluímos que há semelhanças nas falas analisadas quanto à presença de sons estranhos ao sistema fonológico da língua, de unidades repetidas, prolongadas, pausas que se inserem em lugares inesperados, e, sobretudo, à coocorrência de episódios gaguejantes e não gaguejantes no mesmo acontecimento de fala, à heterogeneidade e imprevisibilidade dos sinais linguísticos, que dizem da relação não estável do sujeito com a própria língua. São dessemelhantes pelo fato de que, comparando-se os sujeitos, as marcas linguísticas efetivamente realizadas diferem entre os sujeitos.

Palavras-chave: gagueira, disfluência, singularidade.
\end{abstract}

\begin{abstract}
The heterogeneity and unpredictability of linguistic signals in a stuttered speech make a single event of each speech manifestation. However, this fact is largely ignored in the name of the need for diagnosisestablishing purposes. The heterogeneity entails the singularity of the linguistic signals that characterize stuttering, whereas the ruling-out of any possibility of control stems from its unpredictability. These premises, we believe, should be on the basis of understanding stuttering and of the beginnings of the process of clinical diagnosis. The data of two stutterers, in a situation of spontaneous conversation, were analyzed, with respect to the linguistic manifestations of repetitions, blockages, dental implosives, bilabial clicks (among others) that may affect the continuous/discontinuous nature of speech and potentially shatter the metrical structure of the language. We conclude that there are similarities in both subjects regarding the presence of sounds that are strange to the phonological system of the native language of the subjects, the repeated, prolonged units, pauses that are inserted in unexpected
\end{abstract}

1. UNIP. Campinas, (SP), Brasil. e-mail: celiacarneiro@uol.com.br

2. UNICAMP/IEL. Campinas (SP), Brasil. e-mail: scarpa@iel.unicamp.br - Agradeço o apoio do CNPq, através da Bolsa Pq, no. 301895/2010-4, para o desenvolvimento desta pesquisa. 


\section{CARNEIRO e SCARPA - Singularidade nas manifestações de falas gagas}

places e, mainly, the co-occurrence of stuttered and non-stuttered episodes in the same speech event, the heterogeneity and unpredictability of the linguistic signals, that point to the non-stable relation of the subject with his own language. The dissimilarities are related mainly to the linguistic markers used differently by the subjects.

Keywords: stuttering, disfluency, singularity.

\section{INTRODUÇÃO E OBJETIVO}

A definição da gagueira se assenta sobre fenômenos linguísticos observados ou sentidos na fala do gago, como pausas, repetições, bloqueios, interjeições, tidos como disfluências que perturbam a fluência verbal ${ }^{3}$. Acontece, assim, em uma manifestação de linguagem que, como tal, implica a língua (LEMOS, 1992, 2001, 2006), ou seja, está submetida às suas leis de funcionamento. Daí decorre a necessidade de a gagueira ser abordada como questão linguística.

Nesse sentido, e também a partir da problematização dos conceitos de fluência/ disfluência por Scarpa (1995, 2006 entre outros), mais do que dizer de uma fala fluente ou disfluente, assumimos que esses fenômenos indicam diferentes relações do sujeito com a língua, pois ambos são partes do funcionamento da fala, já que estão presentes em falas gagas e não gagas. Nas palavras de Scarpa (2006, p. 178), "A mesma língua ou as relações do sujeito com a mesma língua que gera(m) a fluência, a gramática, gera $(m)$ também a disfluência, o lapso". No entanto, não provocam o mesmo efeito em um - efeito de fala gaga - e em outro - efeito de fala não gaga.

Há que se ressaltar, ainda, a heterogeneidade e imprevisibilidade dos sinais linguísticos presentes em uma fala gaga que fazem, de cada manifestação de fala, um acontecimento singular, e que são frequentemente desconsideradas em nome da necessidade de um diagnóstico clínico. Da heterogeneidade, depreendemos a singularidade dos sinais linguísticos que caracterizam essa gagueira e, da imprevisibilidade, descartamos qualquer possibilidade de controle.

Ainda que necessário o diagnóstico, essa tentativa de homogeneização resulta na homogeneização dos sujeitos da fala; daí surgem mitos, como o mito da ansiedade, o mito da evitação de situações de fala, o mito da evitação de palavras temidas, o mito de que o gago possui pouco vocabulário, dentre outros. São mitos, presentes em uma certa literatura e também no senso comum, tomados ora como causas, ora como consequências da gagueira, como discutido em outros estudos (CARNEIRO, 2009). Estes mitos se desfazem ou são questionados com contraevidências cada vez mais frequentes na literatura (CARNEIRO, 2009, entre outros)

Certo é que temos um sujeito, efeito do funcionamento linguístico discursivo, que, ao manifestar sua fala, se vê diante de fenômenos linguísticos que, a qualquer momento, sem possibilidade de controle, põem sua fala à deriva, enveredando no inesperado; põem em destaque o movimento, articulatório ou corporal, daquele falante; põem, falante e ouvinte, à escuta dos movimentos da língua; deslocam do

\footnotetext{
3. Conforme a Classificação Internacional de Doenças (CID 10), código F98.5.
} 
sentido para o corpo. Geram tensão no corpo do falante. Geram tensão no ouvinte. O sentido fica suspenso (CARNEIRO, 2006). Com o não gago, o efeito desses sinais linguísticos é outro; não é efeito de língua à deriva; não é efeito de fala gaga.

A gagueira é, assim, o efeito da tensão entre o reconhecimento e o estranhamento dos movimentos da língua em uma fala (CARNEIRO, 2009). Uma tensão que provoca sofrimento.

A imprevisibilidade e heterogeneidade desses sinais linguísticos provam a ausência do controle; comprovam a língua na fala; indiciam o sujeito "efeito do funcionamento linguístico discursivo, já que "toda fala é [...] sintoma de sujeito" (LIER-DE VITTO, 2002, p. 9). E é a presença desses fenômenos - hesitações, repetições, pausas, bloqueios, inserções de sons estranhos à língua ou em contextos fonológicos inesperados - que fazem com que uma fala tenha efeito de fala gaga.

Se é acontecimento singular de fala, "é irredutível, [...] insiste como diferença" (LIER-De VITTO, 2004, p.48). Assim cremos deva ser o trabalho de compreensão da gagueira e deva ter início um diagnóstico em clínica: analisando, interpretando e compreendendo o fenômeno linguístico que faz com que aquela fala seja estranha, incomode o falante e o interlocutor.

A criança vem para a clínica com uma suspeita de gagueira levantada pela interpretação do outro, também lugar de funcionamento linguístico discursivo. Uma interpretação, portanto, não neutra, de que aquela criança é gaga. O adulto vem para a clínica a partir da sua interpretação de sua própria fala. Se essa interpretação traz ou não marcas da interpretação de outro, nesse momento, para o fonoaudiólogo o que está em jogo é a escuta que ele faz. Cabe ao fonoaudiólogo, de uma posição também não neutra, pois também lugar de funcionamento linguístico discursivo, orientar-se linguisticamente para a análise de como a língua está sendo manifestada nessa fala. Dessa posição, ele poderá emitir um parecer sobre a fala da criança ou do adulto. ${ }^{4}$

Em outros termos, a gagueira deve ser analisada como problema linguístico, já que seus sinais se revelam no domínio do simbólico. Assim deve ser, mesmo que qualquer acontecimento físico-fisiológico-neurológico, social ou emocional possa um dia vir a ser posto em relação de concomitância. Estaremos sempre diante de acontecimentos em domínios heterogêneos (CARNEIRO, 2009, p. 56).

Disso advém a importância de um trabalho de análise descritiva linguisticamente orientada de acontecimentos singulares de falas gagas, ou dos sinais que provocam esse efeito. É assim que, neste trabalho ${ }^{5}$, a partir de uma análise linguística, verificamos que, certos fenômenos presentes em uma fala com efeito de fala gaga afetam o campo da língua constituída. A partir dessa análise,

4. Para um aprofundamento sobre as discussões linguísticas e fonoaudiológicas na reflexão sobre falas sintomáticas, sugerimos a leitura dos trabalhos de Lier-De Vitto (1998, 2000, 2004, 2006 e outros) e dos demais integrantes dos Grupos de Pesquisas por ela coordenados no LAEL/PUCSP. Um resumo da leitura desses trabalhos pode ser encontrado em Carneiro (2009, cap. 1, p. 51).

5. Partes da discussão aqui empreendida encontram -se em Carneiro (2009). Nesse trabalho, várias manifestações de falas tidas como gagas foram analisadas e vários conceitos envolvidos nas discussões sobre a gagueira foram ressignificados. 
revisitamos conceitos bem como desmistificamos certas crenças sobre a gagueira.

\section{METODOLOGIA E SUJEITOS.}

Para este trabalho, trazemos acontecimentos de fala de dois gagos adultos, gravados em vídeo-tape ${ }^{6}$, aqui identificados como JR e RM. Desses acontecimentos de fala, destacaremos alguns fenômenos linguísticos mais ilustrativos para nossa discussão.

Nas transcrições, foram utilizadas as notações:

- Trechos transcritos em itálico referem-se à fala analisada. A fala dos entrevistadores está transcrita em fonte normal.

- Trechos de fala extraídos dos diálogos para ilustrar nossa análise serão identificados com a inicial do sujeito seguido do número da linha em que se encontra transcrito. Assim, JR(15), que se lê como linha (15) da fala de JR.;

- O entrevistador vem referido como " $E$ " nos excertos de diálogo analisados.

- Vírgula, ponto-e-vírgula, ponto final, ponto de exclamação e ponto de interrogação foram utilizados em conformidade com as regras de escrita sempre que esse trecho foi sentido como não gaguejante.

- (SI) foi usado para indicar trecho de gravação incompreensível ou inaudível para a transcrição.

- <respiração>; <inspiração> são termos usados para assinalar inspiração e expiração audíveis na gravação.

- O símbolo [ ] (colchetes) é usado para anotações de ocorrências diversas no meio de um trecho de fala. Exemplo:

JR: Acho que foi / dos $P^{\wedge} \operatorname{dez}$ anos / é I [estala a língua - implosiva dental] de idade $[\ldots]$

- O discurso direto é identificado por " " (aspas). Exemplo:

RM: "Bora, gago", "Bora, gaguinho", "vem cá gaguinho, vem cá gaguinho / (SI) jogá bola" [imitando a fala de outros].

* Estes símbolos são utilizados quando a escrita ortográfica não se mostra

6. Esse vídeo está disponível em <http://www.nacaocultural.pe.gov.br/ documentário-gagueiranao-tem-graca-tem-tratamento $>$ sendo, portanto, de domínio público. São gravações realizadas por alunos do curso de Comunicação Social com Habilitação em Jornalismo, da Universidade Católica de Pernambuco (Unicap), em julho/2008. São depoimentos prestados aos entrevistadores que não aparecem nas gravações, sendo possível ouvir suas vozes apenas esporadicamente quando dirigem perguntas aos depoentes com o intuito de levá-los a falar sobre suas falas gagas. 
Cadernos de EsTUDOS LINGüísTICOS (54.1) - Jan./Jun. 2012

O quadro abaixo sumariza demais símbolos utilizados:

\begin{tabular}{|l|l|}
\hline SÍMBOLO & DESCRIÇÃO/ EXEMPLO \\
\hline$/$ & pausa de duração pequena ou média. \\
\hline$/ /$ & pausa mais longa. \\
\hline$:$ & prolongamento de curta duração do som que o antecede. \\
\hline$::$ & prolongamento de maior duração do som que o antecede. \\
\hline$\wedge$ & bloqueio no som que o sucede. \\
\hline$P$ & oclusiva glotal \\
\hline k & oclusiva palatal surda.* \\
\hline S & fricativa palatal surda.* \\
\hline d & implosiva dental.* \\
\hline$\odot$ & clique bilabial.* \\
\hline 6 & mplosiva bilabial.* \\
\hline X & fricativa velar surda.* \\
\hline G & oclusiva uvular.* \\
\hline, & antecede a sílaba tônica. \\
\hline$\cdot$ & $\begin{array}{l}\text { no meio da palavra, indica que houve descontinuidade na produção } \\
\text { articulatória de uma } \\
\text { palavra. Exemplo: RM: a.ssim. }\end{array}$ \\
\hline
\end{tabular}

adequada ou quando pretendemos destacar algum fragmento de fala gaguejante, principalmente em casos de repetição do fone.

De acordo com Merlo (2006), os bloqueios, ou "posição articulatória fixa", ocorrem quando para a produção de um som os articuladores são posicionados, mas sua realização demora a acontecer e, quando ocorre, se dá com excesso de força muscular. Os bloqueios costumam vir acompanhados de mímicas faciais ou outros movimentos corporais, que tornam o esforço muscular visível ao ouvinte. Ainda de acordo com a autora, acontecem, em geral, com palavras iniciadas por consoantes oclusivas ou vogais e raramente ocorrem na fala de sujeitos não gagos. Repetições são, por essa autora, reproduções sucessivas de um mesmo elemento, seja ele segmento (ou fone), sílaba, palavra ou frase. As duas primeiras, repetição de fone ou sílaba, representam rupturas lexicais e as últimas - repetições de palavras ou frases - rupturas sintáticas de sintagmas. Todas elas estão presentes tanto na fala gaga como na fala considerada não gaga, sendo que, enquanto as repetições de segmentos ou sílabas tendem a ocorrer com frequência e com mais de uma repetição do mesmo elemento na fala dos primeiros, elas são raras na fala dos não gagos e, quando ocorrem, tendem a constar de apenas uma repetição. 


\section{RESULTADOS DA ANÁLISE}

\subsection{A fala de JR.}

Esta é uma fala marcada por sons estranhos ao sistema fonológico partilhado pelos falantes do português brasileiro (PB), como oclusivas glotais, implosivas dentais e cliques bilabiais, além de bloqueios e repetições ${ }^{7}$ de sílabas.

Os fenômenos presentes na fala de JR afetam a oposição entre o contínuo e o descontínuo da língua (CARNEIRO, 2009) alteram o efeito do acento frasal e alteram também a estrutura de unidades reconhecidas como palavras, como ilustramos com os trechos de fala abaixo ${ }^{8}$ :

(1) E: Com quantos anos você começou a gaguejar?

(2) JR: Bom, a minha di^dificuldade, ^desde que eu me entendo ${ }^{\wedge}$ por Pgente, assim, sei lá:, Pom cinco anos, seis anos, sei lá [engole] kPeu já venho já com essa^deficuldade / na minha fala, né?

Em JR(2) há retomada de sílaba e bloqueio na segunda sílaba em "di^dificuldade" alterando a estrutura métrica dessa unidade reconhecida como palavra pelo falante do PB. O acento primário em "dificuldade" recai sobre a sílaba [da] e a sílaba [di] poderia, em algumas pronúncias, ser portadora de acento secundário. A repetição gera duas sílabas [di] (di^dificuldade). O bloqueio imprime à agora 'segunda sílaba' [di] uma proeminência extra, fazendo com tenha efeito de tonicidade mais evidente do que a sílaba normalmente acentuada da palavra.

De acordo com Nespor e Vogel (1986), a estrutura prosódica dos enunciados de uma língua é organizada hierarquicamente por um arranjo de proeminências estabelecidas entre seus constituintes. Nessa hierarquia, cada constituinte é organizador de unidades prosódicas inferiores ou dominadas e estruturador de um todo superior ou dominante. De acordo com Nespor e Vogel (1986), essa hierarquia obedece a seguinte ordem: "enunciado" - constituinte mais alto -, "frase entoacional", "frase fonológica", "grupo clítico", "palavra fonológica”, "pé” e a "sílaba" - seu constituinte mais baixo.

O bloqueio também muda o efeito do acento frasal em "(^desde que eu me entendo) ^por Pgente”. " Por gente" seria uma frase fonológica, com cabeça à direita (gente) e com o acento frasal em gen. O bloqueio em ^ por e a oclusão glotal antes e "gente" resulta numa métrica inesperada da frase fonológica em questão, cindindo-a no limite da preposição "por", abrindo uma fronteira prosódica entre "por" e "gente", que soa estranha ao gago e ao não-gago.

O mesmo processo se observa nos outros dois dados abaixo:

7. Para uma discussão sobre esses conceitos, sugiro também a leitura de Britto Pereira (2003).

8. Neste depoimento, as falas dos entrevistadores são pouco audíveis - são falas em "cena de gravação de depoimentos" - razão pela qual usamos, para seu registro, das anotações fornecidas pelos responsáveis pela gravação a quem manifestamos nossos agradecimentos. 
(i) de "com cinco anos" para "Pom cinco anos";

(ii) de "que eu já venho já com essa dificuldade" para "kPeu já venho já com essa ^deficuldade”.

Associe-se a isso a presença da oclusiva glotal, estranha para o PB, em um contexto fonológico em que não cabe uma oclusiva. $\mathrm{O}$ efeito resultante é de outra unidade, com novas conexões e nova configuração prosódica, não necessariamente reconhecidas na língua. Estamos, então, frente a uma das múltiplas faces da heterogeneidade: "a da não-coincidência dessa fala com a da massa falante" (LIERDE VITTO, 2006, p.191). Indício, portanto, do que faz desse acontecimento de fala um acontecimento singular.

Continuando com JR:

(3) E: $\quad$ Como você se deu conta de que gaguejava?

(4) JR: Acho que foi / dos $P^{\wedge} d e z$ anos / é d de idade, nove anos, assim, entendeu, que minha mãe já já vinha, já já vinha me pro já vinha me levando a tratamentos fonoaudiológicos, ai pronto, dai ppp Oor diante, já passei pppor dididiversos especialistas, mas nunca ?onsegui a cura, dotalmente. [ri]

Em JR(4), duas consoantes - a oclusiva glotal e a implosiva dental - não necessariamente reconhecidas pelos falantes nativos da língua surgem em contextos fonológicos inesperados interrompendo a continuidade dos sons anteriores, ou seja, a primeira interrompendo a continuidade impressa pela fricativa e, a segunda, interrompendo a continuidade impressa pelo segmento vocálico "é".

Além disso, nesse mesmo trecho, vemos a continuidade do texto sendo interrompido por retornos em “que minha mãe já já vinha, já já vinha me pro já vinha me"; bem como no retorno do clique bilabial, da consoante inicial em "pppor", da sílaba inicial em "dididiversos", na oclusiva glotal em "Ponsegui" e na implosiva dental em lugar de uma oclusiva dental no início de "dotalmente".

(5) E: $\quad$ Como você enfrenta o problema?

(6) JR: Hoje em dia, eu levo normalmente, normalmente mesmo no meu

trabalho, é:: eu m no trabalho, d normalmente. Agora assim, a dificuldade é porque eu n eu não posso é é exercer ffffunções que lIdem com o público. É isso, entendeu?

Em JR(6), outros são os sinais linguísticos: uma consoante - “ $m$ ” - que se interpõe interrompendo a continuidade das vogais em "é:: eu m no trabalho" e de outra consoante - " $n$ " - que se interpõe em "eu n eu não posso".

Vemos, assim, uma fala entrecortada por sons imprevisíveis que retornam ou surgem em lugares também imprevisíveis. Vemos, também, trechos em que as escansões e retornos gaguejantes praticamente desaparecem para depois ressurgirem em lugares e de modo inesperados:

(7) E: No trabalho?

(8) JR: No trabalho assim, no trabalho não, porque eu não trabalho como público em nada. Agora, se eu vier a procurar outro emprego, dependendo da função que eu for exercer, com certeza irá atrapalhar e muito. 


\subsection{A fala de RM}

O segundo sujeito, RM (20 anos), teve sua fala gravada em vídeo-tape, pelos mesmos entrevistadores e com os mesmos objetivos. São 12 minutos de diálogo em que acontecem muitas repetições de fones e sílabas, muitas ocorrências de uma sílaba constituída por "Ge”, seguida de pausa preenchida.

São escansões sucessivas e reiteradas, tentativas frustradas de reformulação de um texto que muitas vezes se interrompe ou é interrompido pelo outro que parece se incomodar e se adianta como se tentasse fazer progredir o diálogo. Os entrevistadores intervêm nessa fala com mais frequência do que vimos com JR 9 .

Neste acontecimento de fala, ao reproduzir a fala de um outro sobre si, RM ora gagueja ora não gagueja.

Vejamos a fala de RM neste acontecimento particular de fala:
(1) RM: Eu/chutochuto com a / esquerda.
(2) $\mathbf{E}: \quad$ (SI)
(3) RM: Direita / é: tudo ao contrário.
(4) E: Gravando.
(5) RM: Gravando.
(6) E: RM, diz teu nome.
(7) RM: É:: bom agora não / é::tipo é::
(8) E: Como é?
(9) RM: ahn?

[fala seu nome com muitos episódios gaguejantes - esse trecho da gravação foi omitido para preservar a identidade do sujeito]

(10) E: idade?

(11) RM: Vinte anos.

(12) E: Sua profissão?

(13) RM: GeGeGeGe [repete esta sequência por dois segundos, aproximadamente] é еи еи еи еи so:u d' (estala a língua) GeGeGeGeu еи еи

(14) E: Essa informação aí vai ser cortada.

RM diz seu nome com muita dificuldade e não chega a dizer qual é a sua profissão com sequências de reiteradas repetições de "eu”, de estalar de língua e da produção de um som consonantal quebrando a continuidade dessas vogais. Seu interlocutor, em E(14), parecendo não suportar essa fala, interrompe.

(15) E: Com quantos anos você começou a apresentar dificuldade na fala?

(16) RM: $\quad$ Foii: : aGaG ap ap apartir dos / um / ano / um ano / e meio, por aí / aí fl GéGéGé / assim GéGéGé no começo foi um <inspira> susto, né? <inspira> um susto / eu não conseguia falá falá a <inspira> é essas coisas / aai pronto ai:: quando foi? um ano /e meio/com do / GéGéGé dois an [bem baixinho] é que eu GéGé [treme os lábios] eu que GéGé mas ai que eu que eu GéG fui GéGé assim né já fui já [ treme os lábios] pelejá é a falá / a falá [fala alguma coisa bem baixo].

\footnotetext{
9. E assim foi também nas outras análises empreendidas por Carneiro (2009).
} 
Os sons se repetem, prolongam-se, as palavras se partem "ap ap apartir”, as pausas interrompem. Palavras são iniciadas e interrompidas: "aí $f$ ", "com do", "dois na”. Sequências são repetidas: "um susto, né? <inspira> um susto”, "eu não conseguia falá falá”, "é que eu GéGé [treme os lábios] eu que GéGé mas ai que eu que eu”, "eu GéG fui GéGé assim né já fui já”, "pelejá é a falá / a falá". A continuidade da voz que seria permitida pelos retornos da vogal "é" é interrompida pela inserção de uma consoante, por uma inspiração profunda, por um tremor dos lábios.

Em RM(17) e de RM(21) à (25) vemos que, ao reproduzir a fala do outro, ele não gagueja. Já, em RM(19), reproduz a fala de outro e gagueja, indiciando diferentes relações com a língua:

(16)

(17) RM: ahn ahn

Eraa as GaGaGa é a turma as as ai né? GaGaGa a turma achava que GéGé " $R$." GéGé aí ai "Bora, gago”, "Bora, gaguinho”, "vem cá gaguinho, vem cá gaguinho / (SI) jogá bola"

(18) E: E assim, como foi que você se deu conta de que gaguejava?

(19) RM: lá foi lá foi em casa mesmo, em casa. d" "Fica quieto, gago, é: ffala direito" essas coisas.

(20) E: Você já sofreu algum tipo de preconceito (SI)?

(21) RM: Já. Já. Pai, mãe, tia, tio, irmã. "Fala logo, fala direito, vai logo, gago safado". Essas coisas.

(22) E: Tanto na família..

(23) RM: familia.

(24) E: Como na escola...

(25) RM: na escola.

(26) E: No trabalho também tem apelido?

(27) RM: Ahn. No trabalho?

(28) E: Te chamam assim?

(29) RM: Não, chama não. É R. É. R.

[fala seu nome sem gaguejar - essa fala foi omitida para preservar a identidade do falante, uma exigência da regulamentação sobre pesquisas com seres humanos]

(30) E: Deixa eu ver aqui. Em que situação você gagueja mais? (SI)

(31) RM: Sei lá. Quando eu f GéGéGé quando eu fquando eu fff: quando eu/fico nervoso oи титититиito ou титиito $G^{\wedge}$ ansioso ansioso. Ai, que nu / sai nada, rapaz. Eu tttento falar, mas não sai nada.

Em RM(31), é convidado a falar de si. Um texto que deve sustentar sozinho. Nesse texto, há o retorno da fala sobre si mesma constituindo um texto que progride aos pedaços, entrecortado por interrupções, descontinuidades provocadas pela inserção de um som consonantal estranho para os falantes da língua, repetições de unidades que quebram a estrutura morfológica de unidades reconhecidas como palavras, cortes que provocam descontinuidade na produção de uma consoante contínua "fff[ico]" .

E é assim por cerca de 10 minutos $^{10}$, quando, então, RM canta, ou seja, reproduz um texto ensaiado, decorado, e, ao cantar, não gagueja.

10. A transcrição completa dessa fala encontra-se em Carneiro (2009). 
É comum referências a gagos que não gaguejam enquanto cantam. Por um lado, temos no canto o texto ensaiado, decorado, congelado que, de acordo com Scarpa $(1995,2006)$, caracterizam os textos, em geral, com menos disfluências. Por outro lado, são sugestivas, neste ponto, as perguntas pelas quais Didier-Weill inicia sua obra (1999, p. 9): "Por que o homem não se contenta em falar, por que é preciso também que ele cante? Se há um parentesco entre a fala e o canto, qual será ele?". Para dizer em seguida que, a dupla vocação da "sonata materna", através da qual o infans é alçado à condição de humano, "marca o mundo do descontínuo" ou "o campo da lei" onde o sujeito encontrará "o bem e o mal, a esquerda e a direita, o antes e o depois", e o "mundo do contínuo, que encontrará no instante em que soar a música [...] [e] irá se especificar por uma súbita colocação entre parênteses dos limites espaço-temporais que ele recebe da ordem da lei" (Idem, p. 9 - 10). No instante em que soar a música, será "convocado [...] a deixar este lugar [que lhe foi atribuído pela lei simbólica] [e] irá se deslocar [seguindo um "impulso específico" ou "pulsão invocante"] para habitar, de maneira nova, uma quarta dimensão que não é mais estruturada pela lei da fala" (p. 11). Opera-se aí "o milagre da música: quando ela soa, verifica-se que o 'eu', que - enquanto 'não eu' - não sabe o que ouve, crê no que ouve" (p. 14). "Cantar", diz ele, "é o único ato humano sobre o qual se pode dizer que encarna uma invocação à qual o Outro responde, [...] de maneira instantânea: quando canta a voz, é imediatamente a voz do Outro que, através da voz do sujeito, se faz ouvir" (p. 66).

\section{CONSIDERAÇÕES FINAIS}

Dessas falas podemos falar de um igual. São iguais no que se refere à presença de sons estranhos à língua; unidades repetidas, prolongadas; sequências repetidas, interrompidas, retomadas; "palavras" iniciadas, repetidas, interrompidas, segmentadas; pausas que se inserem em lugares e momentos inesperados; bloqueios. São iguais no que se refere à violação do contínuo e descontínuo da língua, à violação da língua constituída pela continuidade das vogais e descontinuidade das consoantes. São iguais no que se refere à violação ou criação de unidades estranhas para os falantes da língua.

E são iguais, principalmente, no que se refere à coocorrência de episódios gaguejantes e episódios não gaguejantes no mesmo acontecimento de fala e quanto à heterogeneidade e imprevisibilidade dos sinais linguísticos nela presentes. $\mathrm{A}$ heterogeneidade e a imprevisibilidade dizem da relação não estática do sujeito com a própria fala, com a língua (estrutura) e com o outro, instância de funcionamento linguístico-discursivo. Indiciam um sujeito que não tem o conhecimento (ou estratégia cognitiva) que o coloca na posição de domínio ou controle da língua, um controle negado, por princípio, pela imprevisibilidade de sua ocorrência. Isso significa descartar qualquer hipótese de controle dessa fala.

No entanto, essas falas são também muito diferentes. Os sons estranhos

à língua não são os mesmos; assim como não são os mesmos os contextos 
fonológicos em que ocorrem, nem são as mesmas as unidades que se segmentam e que se criam. Os sujeitos dessas falas não são os mesmos.

A “determinação das unidades” é questão central no estudo sobre a gagueira já que falas gagas são aquelas em que unidades são criadas, rompidas, segmentadas, violadas pela inserção de pausas, sons estranhos à língua, imprevisíveis. É o lugar ideal em que se observa que "a língua não se apresenta como um conjunto de signos delimitados de antemão" (SAUSSURE, [1916] 1973, p. 120).

Para Saussure, cada unidade linguística, tanto em seu aspecto conceitual como em seu aspecto material, é identificada a partir do valor que adquire na relação que se estabelece entre as outras unidades com as quais se opõe, ou jogo de relações associativas (in absentia) e do valor adquirido nas relações que se estabelecem entre as outras unidades com as quais se combina, ou jogo de relações sintagmáticas (in praesentia).

Lembrando-nos, ainda, e com Saussure, de que para "os falantes [...] tudo o que for significativo num grau qualquer aparece-lhes como um elemento concreto, e eles o distinguem infalivelmente no discurso" (SAUSSURE, 1973, p. 123), a "imprevisibilidade de um acontecimento singular" (ANDRADE, 2003) que rompe ou segmenta unidades reconhecidas da língua cria unidades não reconhecidas, estranhas.

A busca de homogeneização para um diagnóstico ou de uma etiologia significa perder o que faz dessas falas acontecimentos singulares. Não perder de vista a singularidade implica analisar como a língua se apresenta em cada acontecimento de fala.

\section{REFERÊNCIAS BIBLIOGRÁFICAS.}

ANDRADE, L. (2003). Ouvir e escutar na constituição da clínica de linguagem. Tese de Doutorado. São Paulo, LAEL/PUC-SP.

BRITTO PEREIRA, M. M. de. (2003). Análise Lingüistica da Gagueira. SP: AM3 Artes.

CARNEIRO, C. R. (2006). Refletindo sobre a gagueira de um ponto de vista linguístico. Estudos Lingüisticos XXXV, p. 448-453.

CARNEIRO, C. R. (2009). Dos efeitos de gagueira. Tese (Doutorado em Lingüística). Instituto de Estudos da Linguagem, UNICAMP, Campinas.

DIDIER-WEILL, A. (1999). Invocações. Dionísio, Moisés, São Paulo e Freud. RJ: Companhia de Freud.

LEMOS, C.T.G. de. (1992). Los procesos metafóricos y metonímicos como mecanismos de cambio. Substratum, vol. I, no. 1, p. 121-135. . (2001). O que a fala da criança nos diz sobre a língua. In: ÍX Simpósio de Letras e Lingüística, 2001, Uberlândia. Resumos do IX Simpósio de Letras e Lingüística. Uberlândia : Universidade de Uberlândia, p. 20-21.

. (2006). Uma crítica (radical) à noção de desenvolvimento na aquisição de linguagem. In: LIERDE VITTO, M. F.; ARANTES, L. (Org.) Aquisição, Patologias e Clínica de Linguagem. SP: EDUC, v. 1, p. 21- 32 . 
LIER-DEVITTO, M. F. (1998). Os monólogos da criança: delírios da língua. SP: EDUC/FAPESP. (2002). Questions on the normal-pathological polarity. Revista da ANPOLL. São Paulo: EDUSP.

- (2004). Sobre a posição do investigador e a do clínico frente a falas sintomáticas. Letras de Hoje. Porto Alegre, v. 39, n.3, p. 47-59, setembro. . (2006). Patologias da linguagem: sobre as "vicissitudes de falas sintomáticas". In: LIER-DE VITTO, M. F; ARANTES, L. (Org.) Aquisição, Patologias e Clínica de Linguagem. SP: EDUC, FAPESP, p. 183-200.

MERLO, S. (2006). Hesitações na fala semi-espontânea: análise por séries temporais. Dissertação de Mestrado. IEL/UNICAMP.

NESPOR, M.; VOGEL, I. (1986). Prosodic phonology. Dordrecht: Foris Publications.

SAUSSURE, F. (1973). Curso de Lingüistica Geral. SP: Cultrix.

SCARPA, E. (1995). Sobre o sujeito fluente. Cadernos de Estudos Lingüísticos, 29, p. 163-184. Campinas: UNICAMP.

SCARPA, E. (2006). (Ainda) sobre o sujeito fluente. In: LIER-DE VITTO, M. F.; ARANTES, L. (Org.) Aquisição, Patologias e Clínica de Linguagem. SP: EDUC, v. 1, p. 161-180. 